This document is confidential and is proprietary to the American Chemical Society and its authors. Do not copy or disclose without written permission. If you have received this item in error, notify the sender and delete all copies.

\title{
An Electrochemical System for the Study of Trans-Plasma Membrane Electron Transport in Whole Eukaryotic Cells
}

\begin{tabular}{|r|l|}
\hline Journal: & Analytical Chemistry \\
\hline Manuscript ID & ac-2017-048536.R1 \\
\hline Manuscript Type: & Article \\
\hline Date Submitted by the Author: & 11 -Jan-2018 \\
\hline & $\begin{array}{l}\text { Sherman, Harry; University of Nottingham, Pharmacy } \\
\text { Stolnik, Snow; University of Nottingham, Pharmacy } \\
\text { Rawson, Frankie; University of Nottingham, School of Pharmacy }\end{array}$ \\
\hline
\end{tabular}

\section{SCHOLARONE $^{\text {m }}$ \\ Manuscripts}


1 An Electrochemical System for the Study of Trans-Plasma Membrane Electron Transport in Whole Eukaryotic Cells

\author{
3 Harry G. Sherman , Carolyn Jovanovic ${ }^{\star}$, Snow Stolnik ${ }^{\infty}$, Frankie J.Rawson** \\ $4 \nmid$ Division of Regenerative Medicine and Cellular Therapies, School of Pharmacy, University of Nottingham, NG7 2RD, UK \\ $5 \infty$ Division of Molecular Therapeutics and Formulation, School of Pharmacy, University of Nottingham, NG7 2RD, UK \\ $6 \ddagger$ Walgreens Boots Alliance, Nottingham, NG2 3AA, UK
}

7

ABSTRACT: The study of trans-plasma membrane electron transport (tPMET) in oncogenic systems is paramount to the further understanding of cancer biology. The current literature provides methodology to study these systems that hinges upon mitochondrial knockout genotypes, or the detection of ferrocyanide using colorimetric methods. However, when using an iron redox based system to probe tPMET there is yet to be a method that allows for the simultaneous quantification of iron redox states whilst providing an exceptional level of sensitivity. Developing a method to simultaneously analyze the redox state of a reporter molecule would give advantages in probing the underlying biology. Herein we present an electrochemical based method that allows for the quantification of both ferricyanide and ferrocyanide redox states to a highly sensitive degree. We have applied this system to a novel application of assessing oncogenic cell-driven iron reduction, and have shown that it can effectively quantitate and identify differences in iron reduction capability of three lung epithelial cell lines

17 All cells communicate with their environment via external 42 18 electron transfer events. These events are mediated by 43 19 (tPMETs) trans-plasma membrane electron transport systems. 44

20 The development of new techniques to study cellular electron 45

21 transfer via trans plasma membrane electron transport 46 22 (tPMET) is required in order to shed light on its role in cellular 47 23 homeostasis. The development of new assays for such purpos-

24 es can yield new biological insight regarding their function. 48

25 The output of the assays can then be applied for a number of 49

26 broad applications, from the development of biosensors ${ }^{1}$ and 50

27 microbial fuel cells ${ }^{2}$ through to identification of potential new 51

28 targets for therapies in which tPMETs are thought to play a 52

29 part, such as cancer ${ }^{3}$.

30 tPMET plays a fundamental role within mammalian cells by 55

31 facilitating the reduction of ferric iron at the duodenal brush 56

32 broder $^{4}$, and detoxifying iron at the environment-exposed lung 57

33 epithelium ${ }^{5,6}$. It is possible to probe these systems using redox 58

34 mediators such as potassium ferricyanide (FIC) ${ }^{7}$, but to date 59

35 there has been no application of electrochemistry to simulta- 60

36 neously quantitate iron redox states in cancer biology. In this 61

37 paper we provide an electrochemical based platform for study- 62

38 ing tPMET through detection of multiple iron redox states to a 63

39 highly sensitive degree, and by doing so we identify differ- 64

40 ences in the reductive capabilities of tPMET in three mamma- 65

41 lian cancer cell lines.
Iron is an essential micronutrient for all forms of mammalian life ${ }^{8,9,10,11}$. Electron transfer across membranes is typically associated with respiratory electron transport within the mitochondria, but tPMET also plays a role within a multitude of processes ${ }^{12}$ including $\mathrm{pH}$ control and signal transduction ${ }^{13}$, apoptosis $^{14,15}$, antioxidation ${ }^{16}$, and iron homeostasis ${ }^{13,17,18}$.

The tPMET function of the non-transferrin bound iron transport system is evidenced to be mediated by a $\mathrm{NAD}(\mathrm{P})$ $\mathrm{H}$ :oxidoreductase system ${ }^{18}$, ascorbate shuttle mechanism ${ }^{19}$, or ascorbate or AFR-dependant transmembrane reductase system $^{19}$. A widely accepted ferrireductase, duodenal cytochrome $b_{561}$ (Dcytb), has been shown to be expressed in a wide variety of cell types including human erythrocytes ${ }^{20}$, lung epitheli$\mathrm{um}^{21}, \mathrm{~K} 562$ cells $^{22}$, astrocytes ${ }^{23}$, and intestinal origin Caco-2 and HEP-G2 cells ${ }^{24}$. This is interesting as, apart from in the gut, 'free' non-transferrin bound iron (NTBI) is often undetectable, except in cases of iron overload ${ }^{25,26}$. tPMET systems may therefore be present as a protective measure if iron overload does occur, or be present at the plasma membrane of cells in different tissue throughout the body for a yet unknown functionality to those identified. This leads to a hypothesis that the role and upregulation of tPMET in cancer is to reoxidize cytosolic NADH to allow for continued glycolysis ${ }^{3}$, in the case of the Warburg effect ${ }^{27}$ occurring. Work has been carried out to look at the presence of tPMET in non-mitochondrial oxygen consumption, and it has been shown to have involvement not only in mitochondrial knockout $\left(p^{0}\right)$ cells but also for oncogen- 
1 ic cells that possess fully competent mitochondrial activity ${ }^{28}$.

2 In light of tPMET mechanisms being present where there may

3 be yet undiscovered functions, such as in the lung or within 58

4 cancer metabolism in relation to $\mathrm{NADH}^{3}$. It is therefore im- 59

5 perative that we study tPMET in oncology to understand the 69

6 underlying biochemistry, as this may lead to better diagnostic

7 tools and therapeutics. Herein we described the development 61

8 of a method that can be used to study tPMET by identifying 62

9 different redox states of iron simultaneously. We then have 63

10 used this method to identify and differentiate tPMET activity 63

11 between cell types of the same tissue and origin - lung epithe- 65

12 lium, as there has not been any comparison between cancerous 66

13 cell lines tPMET activity in this manner.

14 The techniques used to study components of iron 68

15 homeostasis ${ }^{29}$ can include potentiometry, which has been used 68

16 to assess redox properties of duodenal cytochrome $b_{561}$. Mac- 79

17 kenzie et $\mathrm{al}^{30}$ have used voltage-clamp experiments in eluci- 71

18 dating how the divalent metal transporter 1 (DMT1) mediates 71

19 both $\mathrm{H}^{+}$-coupled $\mathrm{Fe}^{2+}$ transport in whole oocytes ${ }^{31}$. Others 72

20 have used double electrochemical mediator systems to look at 73

21 intracellular redox sites ${ }^{32}$. Baronian et $\mathrm{al}^{33}$ have also used line-

22 ar sweep voltammetry in the electroanalytical detection of 75

23 catabolism in whole cell yeast. McDowall et $\mathrm{al}^{34}$ have used 76

24 amperometry to study the lysates of neuroblastoma cells, but 77

25 do not investigate whole cell neuroblastoma cells and there- 78

26 fore they could not assess tPMET. Cancer tPMET (on intact 79

27 cells) has been investigated by alternative methods to electro- 80

28 chemistry. Herst et $\mathrm{al}^{3,35}$, Berridge et $\mathrm{al}^{36}$ and Scarlett et $\mathrm{al}^{37} 81$

29 have all used mitochondrial gene-knockout $\left(\mathrm{p}^{0}\right)$ cells as a way 81

30 to study tPMET. Using HL60 $\rho 0$ cells they have demonstrated 83

31 a link between tPMET and cell surface oxygen consumption, 84

32 linked to the Warburg effect ${ }^{27}$. Avron and Shavit ${ }^{38}$ previously 85

33 developed a colorimetric assay to determine ferrocyanide 86

34 (FOC) concentration, which could be used to study tPMET. 87

35 This was improved upon by Lane et $\mathrm{al}^{7}$, and used to study

36 tPMET in a leukaemia cell line. These two colorimetric meth- 88

37 ods provide sound methodology to study tPMET at a high 89

38 throughput level, but as they only quantitate for FOC they lack

39 ability to quantify both iron redox states present. In the pre- 90

40 sent work we develop an electrochemical assay capable of 91

41 monitoring and quantifying the redox states of iron to provide

42 new biological observation on the use of tPMETs in cancer 92

43 cell lines.

We have developed an electrochemical assay using linear 95 sweep voltammetry at a microelectrode, and in a first have 96 subsequently applied this to study tPMET in cancer cells. We 97 have developed a micromolar-level iron quantification method 98 that is simple, with exceptionally low limits of detection, and 99 that improves on current techniques to study tPMET on wholq 00 cells by allowing multiple redox state detection. This has led 01 to new observations that cells from the same tissue behavq 02 differently in terms of how they use tPMET. This raises somq 03 interesting questions about the underlying biology and theif 04 function. This new application for electrochemistry has been 05 fully validated with other analytical techniques which includq 06

107 biological toxicity assays and ICP-MS analysis of cellular iron content.

\section{Experimental section}

Materials. All reagents were purchased from Sigma-Aldrich, unless otherwise stated.

Characterisation of FIC/FOC redox states for calibration. $0.01 \mathrm{mM}$ FIC and FOC (Acros Organics) solutions were both made in Hanks' Balanced Salt Solution (HBSS). The two solutions were mixed in a variety of combinations, from ratios 10:0 to $0: 10$ FIC:FOC to give concentrations $(\mu \mathrm{M})$ of each redox state respectively at: $0: 10,1: 9,2: 8,3: 7,4: 6,5: 5,6: 4$, $7: 3,8: 2,9: 1$ and $0: 10$.

A three electrode system comprising a $33 \mu \mathrm{m}$ carbon fibre working microdisk electrode, a saturated calomel reference electrode, and a platinum wire counter electrode was used (ALS Co. Ltd, Japan). An Autolab PGStat302A potentiostat with low current detection module (ECD) (Metrohm Autolab, Utrecht, Netherlands) and NOVA 2.1 software was used in all experiments.

Linear sweep voltammetry was performed with solutions containing differing ratios of oxidized and reduced forms of iron (as above) and were carried out by scanning from $500 \mathrm{mV}$ to $150 \mathrm{mV}$, at a scan rate of $10 \mathrm{mV} \mathrm{s}^{-1}$. A current range of 100 pA was used, with a low current module employed. A linear sweep voltammogram was recorded with the HBSS only acting as a control to allow for baseline subtraction. Between each solution tested the microelectrode was polished for 4 minutes using a PK-3 electrode polishing kit (ALS Co. Ltd, Japan). Pseudo-steady-state values were determined by assessing a first derivative function of the voltammogram and cross referencing with the original curve to clarify that this was the voltage the pseudo-steady state was located.

Stability of FIC in cell culture conditions. As outlined in Method S-1 of Supplementary Information.

Investigation of electrode fouling. As outlined in Method S2 of the Supplementary Information.

Growth study. The three cell lines analyzed in this study were Calu-3, H1299 and A549 cells. All cell lines were originally purchased from ATCC. All cells were grown in DMEM (Dulbecco's Modified Eagles Medium) containing high glucose supplemented with $10 \%$ FBS (fetal bovine serum), $100 \mathrm{U} / \mathrm{ml}$ penicillin, $100 \mu \mathrm{g} / \mathrm{ml}$ Streptomycin and $24 \mathrm{mM}$ HEPES (N-(2Hydroxyethyl) piperazine-N'-(2-ethanesulfonic acid)) buffer. A549 cells were passage number 12 for the growth study, H1229 were passage number 13 and Calu-3 passage number 41. A549 and H1299 cells were seeded at $0.10 \times 10^{6}$ cells/well and Calu- 3 cells at $0.25 \times 10^{6}$ cells/well in 12 well plates. Viability was tested each day for 10 days by first detaching cells from cell culture plates using $0.1 \mathrm{~mL}$ trypsin/EDTA, followed by addition of $10 \mu \mathrm{l}$ cell suspension to $10 \mu \mathrm{l}$ tryphan blue dye (TB). Dye exclusion analysis was then carried out using a Tecan microplate reader (Tecan Ltd, Weymouth, UK). A 
1 growth curve was produced for each cell line, and a harvesting 57

2 time selected that ensured all three cell lines were in an expo- 58

3 nential growth phase when used in subsequent experiments. 59

4 Calu-3 cells were hence harvested after a 4 days growth, and 60

5 A549 and H1299 cells following 3 days growth. All cells were 61

6 harvested at a confluency of $\sim 90 \%$.

7 Toxicity studies. The choice of buffer to use for preparing 64

8 FIC, and its effect on cellular membrane integrity was evaluat- 65

9 ed using Lactate Dehydrogenase (LDH) assays (Tox7 Sigma- 66

10 Aldrich) in 96-well plate format. Cells were plated in densities 67

11 corresponding to the above determination, at $8.4 \times 10^{4}$

12 cells/well for A549 and H1299, and $21.0 \times 10^{4}$ cells/well for 68

13 Calu-3 cells. A549 cells were passage 20-24, H1299 passage 69

14 21-25 and Calu-3 passage 33-35.The three cell lines were in- 70

15 cubated with either 0.01M PBS (Phosphate Buffer Saline) or 71

16 HBSS (Hanks' Balanced Salt Solution) for 2 hours $\left(37^{\circ} \mathrm{C}, 5 \% 72\right.$

$17 \mathrm{CO}_{2}$ ). Each concentration was triplicated. Following the incu- 73

18 bation the LDH assay was performed using the manufacturer's 74

19 recommended method. This involved removing $75.0 \mu \mathrm{l} /$ well of 75

20 the cell-conditioned sample solutions and transferring to a

21 fresh, clear 96-well plate. To these solutions $150.0 \mu \mathrm{l} /$ well 76

22 LDH reagent was added and the plate incubated at room tem-

23 perature in the dark for 25 minutes. Immediately after this the 77

24 absorbance was measured at $492 \mathrm{~nm}$, using a Tecan microplate 78

25 reader. Plate absorbance was measured at $690 \mathrm{~nm}$ and sub- 79

26 tracted prior. Blanks were set up that consisted of the same 80

27 HBSS or PBS solution used for cell-incubations, and LDH 81

28 added as above, their values then subtracted from the appro- 82

29 priate measurement. Relative LDH release was calculated by 83

30 setting the absorbance for the untreated cell control (DMEM) 84

31 as $0 \%$, and the positive control $(0.2 \%$ Triton $\mathrm{X}-100)$ was as- 85

32 sumed to result in total cell lysis and set at $100 \%$.

33 To determine the effect on metabolic rate of FIC solution in 88

34 HBSS, we used the MTS ([3-(4,5-dimethylthiazol-2-yl)-5-(3- 89

35 carboxymethoxyphenyl)-2-(4-sulfophenyl)-2H-tetrazolium) 90

36 assay (CellTiter 96®), Promega) in 96-well plate format. Cells 91

37 were seeded as described above for the LDH assay. The three 92

38 cell lines were incubated with various concentrations $(0.001,93$

$390.01,0.1,1,2,5,10,25,50,100 \mathrm{mM})$ of FIC in HBSS for 294

40 hours $\left(37^{\circ} \mathrm{C}, 5 \% \mathrm{CO}_{2}\right)$. Following incubation, cells were

41 washed once with warm PBS and incubated with $20.0 \mu$ l MTS 95

42 reagent in $100 \mu \mathrm{l}$ DMEM (without antibiotics, 10\% fetal bo- 96

43 vine serum (FBS)) per well for 2 hours at $37^{\circ} \mathrm{C}$ and $5 \% \mathrm{CO}_{2} .97$

44 Absorbance readings and blank subtractions were taken as 98

45 described for the LDH assay. Blank subtractions consisted of 99

46 DMEM with $10 \%$ FBS added, without antibiotics. Relative 00

47 metabolic activity was calculated by setting the absorbance fol 01

48 the untreated cell control (grown in DMEM) as $100 \%$, and the 02

49 positive control ( $0.2 \%$ Triton X-100 solution) was assumed td 03

50 result in total cell lysis and set at $0 \%$.

51 Electrochemistry on FIC incubated with cells for twd 06

52 hours. A549 cells were passage 17-19, H1299 passage 17-21 07

53 and Calu-3 passage 28-29 for these experiments. The three cell 08

54 lines were seeded at $6.3 \times 10^{5}$ cells/well for Calu-3 cells and 09

$552.5 \times 10^{5}$ cells/well for A549 and H1299 cells, in a 6 well platd 10

56 and cultured in DMEM as outlined in the growth study sec 111 tion. The growth medium was removed and each well washed three times with phosphate buffer saline (PBS). Solutions containing only FIC $(0.01 \mathrm{mM}, 2 \mathrm{ml})$ was added to the wells and the plates incubated for 2 hours $\left(37^{\circ} \mathrm{C}, 5 \% \mathrm{CO}_{2}\right)$. After the incubation $1 \mathrm{ml}$ of the supernatant was removed for electrochemical investigation. All parameters and procedures for electrochemical analysis were followed as outlined above. HBSS buffer was processed as the samples allow for normalisation of the electrochemical data by removing any electrochemical signals arising from the buffer. Bicinchoninic acid assay was carried out as described in Method S-3.

pH testing of Hanks' Balanced Salt Solution (HBSS) and $0.01 \mathrm{mM}$ Ferricyanide (FIC), before and after cell incubation. As outlined in Method S-5 of Supplementary Information.

Inductively coupled plasma mass spectrometry (ICP-MS) to quantitate cellular iron content. As outlined in Method S-6 of Supplementary Information.

\section{Results and Discussion}

It is paramount that we develop new systems to study transplasma electron transport (tPMET) and iron redox chemistry in biological systems. These two areas of study have been implicated within cancer biology $y^{3}$, and play an instrumental role within iron uptake mechanisms ${ }^{39,40}$. The challenge research currently faces is that eukaryotic cells are notoriously temperamental and subject to extracellular and environmental change. Additionally, when looking at iron redox, FOC is detected as opposed to FIC, where simultaneous detection could be advantageous. This detection of FOC production as opposed to FIC loss is attributable to the poor sensitivity of FIC due to a low extinction coefficient at the $420 \mathrm{~nm}$ detection wavelength $^{7}$. In line with this task we have applied electrochemistry to produce an iron quantification system that does not induce cytotoxicity within our cell lines, whilst matching the current world-leader for lower detection limits and improving on this through the simultaneous quantification of two iron redox states.

Calibration curve for iron quantification. Our chosen iron compound for analysis of extracellular reductive capability is FIC with a well-known one electron redox couple ${ }^{29,32,41}$. FIC used in cellular based experiments to report on cellular iron reduction because FIC $\left(\mathrm{Fe}^{3+}\right)$ can be reduced to FOC $\left(\mathrm{Fe}^{2+}\right)$ via cellular membrane bound reduction systems ${ }^{42}$. To assess the redox state of iron linear sweep voltammetry was employed $^{32,33}$. The method works by assessing a shift in current values of the current/voltage curve generated within the voltammogram, which indicates a change in the redox state of the iron compound. This is demonstrated in Figure S-2, and the corresponding calibration curve is displayed in Figure S-3. Cathodic currents (negative values) are indicative of FIC reduction and anodic current (positive current) values represent FOC oxidation. By identifying the position of both steady state anodic and cathodic currents we were therefore able to identify the quantity of FOC and FIC and therefore quantify iron 
1 redox state changes in solution. To allow for this quantifica- 44

2 tion we carried out a characterization study with known con- 45

3 centrations of our redox states, thus producing a calibration 46

4 curve (Figure S-3). The experiment was carried out at the

5 same conditions as all subsequent electrochemical experiments 47

$6\left(10 \mathrm{mV} \mathrm{s}^{-1}\right.$, and at $\left.37^{\circ} \mathrm{C}\right)$. This also allowed for the determina- 48

7 tion of our lower limit of detection (LOD), calculated using 49

8 the method outline by Armbruster et $\mathrm{al}^{43}$. The total iron con- 50

9 centration was kept constant at $0.01 \mathrm{mM}$ whilst only the ratio 51

10 of oxidized:reduced state was varied. Determination of steady- 52

11 state was by visual inspection of the first-derivative plot. The 53

12 potential at which the line intersected the $\mathrm{x}$ axis whilst also 54

13 maintaining a horizontal plateau was selected and the current 55

14 noted for this point, these current values were then plotted 56

15 against the known concentrations. The calibration plot gener- 57

16 ated had a $\mathrm{R}^{2}$ value of 0.987 for FOC and 0.995 for FIC, as 58

17 shown in Figure S-3. The equations that are used in all later 59

18 experiments for determination of iron concentration are also 60

19 displayed in Figure S-3, where y is the current and $\mathrm{x}$ is the 61

20 concentration of iron.

21 The production of FOC by cells has been previously deter- 64

22 mined using colorimetric methods, most notably by Lawen et 65

$23 \mathrm{al}^{7}$. We calculated our $\operatorname{LOD}^{43}$ at $0.44 \mu \mathrm{M}$ for FOC and 0.9766

$24 \mu \mathrm{M}$ for FIC, indicating we are within the same order of magni- 67

25 tude for our system. When calculating our LOD for FOC de- 68

26 tection we took our 10:0 FIC:FOC sample $(0 \mathrm{mM} \mathrm{FOC})$ to be

27 our blank and 9:1 FIC:FOC (0.001 mM FOC) to be our lowest 69

28 concentration. We did this as we needed the steady- state an- 70

29 odic current value to use for the calculation. HBSS displays no 71

30 faradaic current, and therefore it is impossible to test this as a 72

31 blank.

32 However, HBSS was tested under the same conditions and 75

33 subtracted against all electrochemical analysis of iron, there- 76

34 fore normalizing our data to account for the non-faradaic elec- 77

35 trochemical contribution from the supporting electrolyte. The 78

36 LOD calculated using this method provided us with a value in 79

37 picoamperes, this was then converted into a concentration 80

38 using our system sensitivities, derived from our equations 81

39 obtained via Figure S-3.

42 Figure 1. Growth study analysis of Calu-3, A549 and H1229

$43 \mathrm{H} 1299$ seeded at 100,000 cells/well. Growth profiles show cleal 00 lag, exponential and plateau phases. Harvesting times were chosen to be within exponential growth phase. Viability was tested using tryphan blue. $\mathrm{N}=1, \mathrm{n}=3$.

The system sensitivity for FOC was $4.67 \mathrm{pA} / \mu \mathrm{M}$, and for FIC the sensitivity was $4.16 \mathrm{pA} / \mu \mathrm{M}$. This method was applied for all subsequent iron quantification within additional electrochemical experiments. The same method as above was applied to calculate the LOD for FIC, except cathodic steady-state current values were used. The $95 \%$ prediction bands shown in Figure S-3 show that our data are very precise, with an average $95 \%$ prediction band value of $+/-3.71$ picoamperes for the linear regression of FOC and +/- 2.20 picoamperes for FIC. This relates to all future values being expected to be within $+/$ $0.89 \mu \mathrm{M}$ of the regression line for FOC, and $+/-0.52 \mu \mathrm{M}$ of the regression line for FIC. This method is also highly precise due to the base subtraction method employed, whereby a buffer-only sample is electrochemically analyzed and is subtracted from the FIC/FOC containing sample, thus removing all chemical noise contribution. If there is no species present within the FIC/FOC sample that passes higher faradaic current than the concentration of FIC/FOC used, then by subtracting the noise in the form of a non-FIC containing blank the analyzed current consist solely of FIC/FOC, and thus vastly reduces the chance of interfering electrochemical species and allowing for highly precise electrochemical analysis.

Growth parameters and toxicity. To begin our cell work we selected three oncogenic cell lines that would allow us to determine whether there was a link between growth rate and their ability to reduce extracellular iron. The chosen cell lines all originate from lung epithelium, and are well characterized within the literature $e^{44,456}$. It was important to assess the cells growth patterns to ensure cells were harvested within the same growth phase, and to elucidate the cell viability when grown in ideal conditions (FBS-supplemented cell culture medium). This was important because if not within the same growth phase the cells would not be directly comparable, and if the cells viability was compromised we would not be analyzing a repeatable system. Therefore we performed a growth study (Figure 1). Assessment of growth rate was done using a Tecan plate reader with cell counting and viability functions and needed optimizing which is discussed in SI Method S-4. As can be seen from Figure 1, our growth curves show a defined lag, exponential and plateau phases. Harvesting time was chosen at three days for H1299 cells and A549 cells, and four days for Calu-3 cells. These times were chosen as all cell lines would then be in the same phase of growth, but also the cell number for Calu-3 cells would be more comparable to A549 and H1299 cells after four days. We needed to determine the doubling time of the cells to have a quantifiable measure of the proliferative rate of the cells (also tell you about the cell cycle is effected by toxicity). Doubling time was determined by taking the same portion of the exponential phase, 200,000 to 400,000 cells $/ \mathrm{ml}$, and calculating the time taken in days to achieve this doubling. H1299 cells had the quickest doubling time at 0.816 days, followed by A549 cells at 1.123 days, and finally Calu-3 cells at 3.804 days. The doubling times achieved mimic the literature for A549 and H1299 cells ${ }^{47}$, and 
3
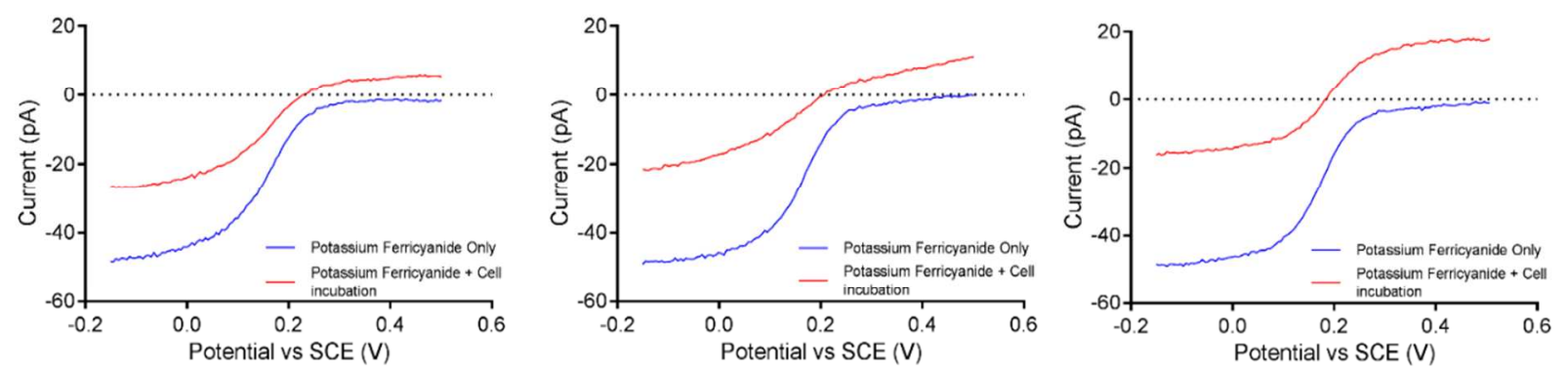

5 Figure 2. Examples of linear sweep voltammogram obtained for each cell line. Cell were exposed to solutions of 0.01 potassium ferricyanide for 2 hours prior to supernatants being taken for electrochemical analysis. Calu-3 (left), H1299 (middle), A549 (right). Hank's Balanced Salt Solution (HBSS) buffer with $0.01 \mathrm{mM}$ potassium ferricyanide in the absence (blue) and presence (red) of cells. Scan rate, 10 $\mathrm{mV} \cdot \mathrm{s}^{-1} \cdot \mathrm{N}=3, \mathrm{n}=3$.

9 types we have chosen therefore allows us to compare A549

10 and H1299 cells which have a similar doubling rate of 0.816

11 and 1.123 , with the less proliferative cell line Calu-3. It was

12 important that we checked cell viability to ensure we were

13 not providing a stressful environment to the cells, which in

14 turn can cause changes in metabolism ${ }^{48}$. Cell viability in

15 ideal conditions, as demonstrated on the right-hand axis of

16 Figure 1, demonstrates the cell lines are in a favorable envi-

17 ronment prior to treatment with iron.

18 Having characterized the growth system for this experiment

19 the choice of buffer to be used as our supporting electrolyte,

20 as well as any cytotoxicity in response to FIC/FOC, was

21 analyzed. The employment of a highly sensitive electro-

22 chemical system meant the presence of electrochemically

23 active species in the supporting electrolyte had to be consid-

24 ered, as they may have contributed to the signal that was

25 collected. Additionally, the supporting electrolyte had to be

26 the correct osmolality to ensure cytolysis did not occur, and

27 that the cells did not undergo undue stress. Two commonly

28 used salt-based cell culture buffers were tested - PBS and

29 HBSS. The main differences between these buffers are their

30 salt components, in addition to the presence of magnesium

31 ions, calcium ions, and D-glucose within HBSS.

32 PBS was chosen as it is a more minimal salt buffer in com-

33 parison to HBSS, thus there would be little scope for it to

34 electrochemically interfere with our analytical signal. HBSS

35 was chosen as, although it has more components, the added

36 magnesium and calcium are important for cell adhesion, and

37 the D-glucose present provided a substitute for serum ensur-

38 ing the cells had an energy source. An LDH assay and the

39 MTS assay was performed with cells exposed to the differ-

40 ent electrolyte. The LDH assay measures cell membrane

41 integrity and so gave us an indication of whether the mem-

42 brane was perturbed, which is indicative of cell death. Iron

43 interferes with the LDH assay so only buffer was assessed

44 here. The MTS assay measures metabolic activity, and 45 therefore is indicative of sub-lethal toxicity. Iron cytotoxici-
46 ty was assayed in this way, after a suitable buffer was cho47 sen. This allowed us to indirectly assess irons effect upon 48 membrane integrity as the MTS assay was carried out with 49 iron in solution with the preferred buffer.

50 LDH assay data is shown in Figure S-6A. It demonstrates 51 that HBSS is the preferred buffer, relative to PBS, although 52 the LDH release is relatively low in both cases. The MTS 53 assay data on toxicity of FIC is displayed in Figure S-6B, 54 and demonstrates FIC in HBSS does not become cytotoxic 55 over two hours until $\sim 10 \mathrm{mM}$ concentration. This meant that 56 our chosen concentration of $0.01 \mathrm{mM}$ was suitable. The 57 LDH and MTS assays data are discussed in further detail in 58 the Figure S-6 section of the Supplementary Information.

59 Electrochemical analysis of cell-incubated samples. The 60 cell culture conditions and electrochemical assay that we 61 developed and characterised were used to assess the cells 62 ability to reduce FIC to FOC. Solutions of FIC were first 63 analyzed by generating a linear sweep voltammogram 64 (LSV) of FIC solutions only (Figure 2). The solutions of 65 FIC were incubated with the cells for two hours at $37^{\circ} \mathrm{C}$ and $665 \% \mathrm{CO}_{2}$, before LSVs were generated of the supernatants of 67 the incubated FIC samples (Figure 2). FIC only samples 68 (Figure 2, blue) produced only cathodic (reductive) cur69 rents, with the anodic steady state plateauing at $0 \mathrm{pA}$, thus 70 indicating the absence of FOC. Upon incubation with each 71 cell line an upward shift in the current measurements was 72 observed (Figure 2, red), indicating a shift of redox states 73 to both FOC and FIC. When incubated with the cells we can 74 deduce that FIC is reduced to FOC, and thus when we scan 75 across our potential range both oxidation and reduction oc76 curs as both redox states undergo electron transfer. It can 77 clearly be observed visually that Calu-3 cells (left) reduce 78 less iron than H1299 (middle), and H1299 cells in turn re79 duce less than A549 cells (right). It is also apparent that 80 there is a slight change in the shape and half-wave potentials 81 of the voltammograms. We suggest that this may be due to 82 minor changes in the $\mathrm{pH}$ of the solutions and potential $\mathrm{pH}$ 
discrepancies between HBSS and FIC after cell incubation. 2 The $\mathrm{pH}$ data is presented in Figure S-7 and discussed there3 in. It is well established that $\mathrm{pH}$ can affect the half-wave 4 potential of such electrochemical reactions as we have pre5 viously reported ${ }^{32}$.
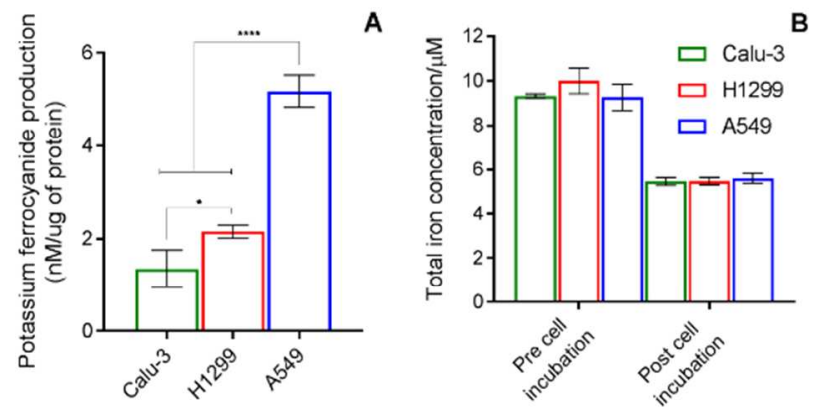

Figure 3. Electrochemical analysis of cellular reduced 0.01 $\mathrm{mM}$ potassium ferricyanide in Hank's Balanced Salt Solution (HBSS) buffer. (A) Concentration of potassium ferricyanide produced, normalized by protein quantification. Statistical analysis was carried out using a one-way ANOVA with Tukey's multiple comparisons test at $\mathrm{P}=0.0453$ for Calu- 3 vs H1299, and $\mathrm{P}=0.0001$ for all other comparisons. $\mathrm{N}=3, \mathrm{n}=3$. (B) Total iron concentration before and after cell incubation. Pre cell incubation samples are significant to $P=0.0001$ for all cell types, compared to post cell incubation samples. This was determined by two-way ANOVA with Sidak's multiple comparisons test. SEM error bars shown $N=3, n=3$. Cell appear to be viable in optimal conditions, and undergo stress when transferred into an alternative medium.

Quantification of iron reduction and comparison between cell types. Quantification of the iron reduction was calculated using steady states from both FIC only (Figure 2, blue) and FIC/FOC after cell incubation (Figure 2, red) samples from Figure 2. Determination of steady states and subsequent iron quantification calculations employed the same method outlined for our calibration plot. The steady states for these calculations were determined using the data presented in Figure 2 (blue and red), once again using the method outlined for our calibration plot. Figure 3A shows the amount of FOC produced by the cell lines, which has been normalised for the amount of protein present in each well plate, thus allowing direct comparison between cell lines. The amount of FOC produced in $\mathrm{nM}$ per ug of protein was 1.25, 2.18 and 5.19 for Calu-3, H1299 and A549 cells respectively. The significance of these results was determined using an one-way ANOVA with Tukey's multiple comparison test, which showed significance between Calu-3 and H1299 reduction of $p=0.0084$ and A549 to all other cell lines of $p=0.0001$. The robustness of our system in analysing this reduction is also demonstrated with our low coefficients of variation (\%CVs) internally between cell samples, at $15.80,7.41$ and $6.58 \%$ for Calu-3, H1299 and
A549 cells respectively. The importance of these results is indicated when taking data from our doubling times data, mitochondrial metabolic rates, and Figure 3A. We can observe that there is no link between the doubling time, and therefore cell cycle differences between the cells, and the amount of FOC produced. In addition, there is no link between mitochondrial metabolic rate and FOC production. Although FOC production is increased when comparing our least proliferative cell line (Calu-3) to our other two (A549 and H1299), we would expect H1299 to have a marginally higher reductive power in relation to A549 cells, or at least to have a similar reductive power when comparing to proliferation, but A549 cells reduce $3.01 \mathrm{nM} / \mathrm{ug}$ of protein more FIC than H1299 cells. Our rationale behind a possible link with mitochondrial metabolic rate and therate of tPMET activity was that higher metabolic rate cells would have a faster turnover of reversible redox couples, and as such have more capability to reduce iron via tPMET. This was not the case, where Calu-3 cells with the highest metabolic rate reduce the least iron (and therefore have the lowest tPMET activity) whilst H1299 with the lowest mitochondrial metabolic rate have a higher tPMET activity. This highlights how important it is to study tPMET systems in biology, as there is evidently much to be understood about how the underlying biology and biochemistry of the cells affects these transport mechanisms. It has been suggested ${ }^{18}$ that trans plasma membrane electron transport (tPMET) can occur via two mechanisms: either through membrane-bound oxidoreductase activity, or through a shuttle-based system exporting reducing equivalents. We hypothesise that a mixture of these systems is in play here, and in subsequent research will hope to elucidate the exact mechanisms of the reduction we have detected here, in addition linking the biological causes of these cell lines have differing reductive capabilities.

Figure 3B shows the quantification of total iron concentration. We observe a reduction in total iron concentration across all cell lines after incubation with the cells. This is significant at $p=0.001$ for all cell lines, as assessed by twoway ANOVA with Sidak's multiple comparison test. It was important to demonstrate that FIC was not entering the cell as the goal of these investigations was to study tPMET and not iron reduction via internal electron transfer systems inside of the cell. A landmark paper by Keilin et al ${ }^{49}$ showed that FIC does not cross the plasma membrane. However we wished to confirm this and therefore performed ICP-MS to quantitate cellular iron. With the premise being if FIC was entering the cell we would see an increase in cellular iron content when cells were incubated with solutions of FIC versus in its absence.

Our data represented in Figure S-8 corroborates with Keilin et al, and proves for our system that the iron content of the cell is not affected by incubation with FIC. This in turn means that neither FIC nor FOC are entering into, or adhering onto the surface of the cells. Iron content values per cell for HBSS incubated samples were $0.14,0.12$ and $0.13 \mathrm{pg}$ for Calu-3, H1299 and A549 cells respectively, and 0.15, 0.12 and $0.10 \mathrm{pg}$ respectively for FIC incubated samples. Two- 
1 way ANOVA with Sidak's multiple comparison test showed

2 no significant different with between HBSS or FIC incubat-

3 ed samples, and no significant difference between cell lines.

4 The iron content of the cells appears to be in line with the 5 literature when normalised for cell number, Mathiasen et al $6{ }^{50}$ present iron levels for mesenchymal stem cells of 0.48 $7 \mathrm{pg} / \mathrm{cell}$, Mojic et al ${ }^{51}$ present values of $0.3 \mathrm{pg} / \mathrm{cell}$ for pros8 tate cancer cell lines LNCaP and PC3, and although an un9 treated sample is not shown, Kumar et al ${ }^{52}$ present A549 10 cells as having $\sim 2.8 \mathrm{pg}$ of iron/cell when incubated with 11 superparamagnetic iron oxide nanoparticles, indicating that 12 pictograms are in line with expected values. Another im13 portant point to note is that our stability data indicates this 14 reduction in total iron concentration cannot be from instabil15 ity and subsequent deterioration of the redox couple under 16 variable conditions. In addition to this we tested whether the 17 electrode would be fouled by using cell-incubated material 18 to ensure that this was not the cause of total iron reduction 19 (SI Figure S-4). We performed the analysis on cells in PBS 20 as the membrane integrity for PBS incubated cells was low21 er (LDH assay, SI Figure S6) and thus there would be more 22 potential for electrode fouling by released components. We 23 found there to be no evidence of electrode fouling, as 24 demonstrated by paired t-test of a $0.01 \mathrm{mM}$ FIC solution 25 electrochemically analysed before and after the microelec26 trode has been used with a cell-incubated sample, at $\mathrm{p}=$ 27 0.1406. In light of our findings, we would therefore tenta28 tively suggest that FIC and/or FOC is interacting electrostat29 ically with a cell-effluxed molecule, thus resulting in a 'loss' 30 of FIC and/or FOC from the supernatant.

31 Interestingly, this detection of a change in total iron concen32 tration highlights one of the major advantages of using an 33 electrochemical method to quantitate FOC production. Im34 proving on the colorimetric methods of Lane et al, and 35 Avron and Shavrit, our system allows for the quantification 36 of both the oxidised and reduced states, as opposed to only 37 the reduced state. This advancement is already having high38 ly relevant and impactful ramifications, as it has flagged 39 interesting findings in our system that would not have been 40 detected if we had employed the colorimetric method. Com41 bined with matching Lane et al as the current world-leader 42 in detection limit for FOC, this provides a very robust sys43 tem to analyze cellular-induced FOC production. Addition44 ally, another interesting advantage is the lack of requirement 45 for addition of acid to the sample.

\section{Conclusion}

47

48 Here we have demonstrated a novel application for analyti49 cal electrochemistry by quantitating cellular iron reduction 50 in oncogenic eukaryotes, and by doing so have created a 51 highly sensitive system that can be used to detect quantities 52 of both FIC and FOC simultaneously. The technique con53 tends with the current world leaders for detection limits of 54 FOC, and provides a detection limit for FIC also that is 55 within the same order of magnitude. We have used linear 56 sweep voltammetry to assess the iron reduction capability of 57 three lung cancer cell lines, and link this to the proliferative

\section{ASSOCIATED CONTENT}

\section{Supporting Information}

77 The Supporting Information is available free of charge on the 78 ACS Publications website.

79 Stability of FIC in cell culture conditions. Simultaneous quanti80 fication of iron redox states for the stability of FIC and FOC at $8137^{\circ} \mathrm{C}$ and $5 \% \mathrm{CO} 2$. Bicinchoninic acid assay. Cell mycoplasma 82 testing. Iron redox state concentration calibration study. Cali83 bration curve for potassium ferrocyanide (FOC) and potassium 84 ferricyanide (FIC). Assessment of growth rate using a Tecan 85 plate reader with cell counting and viability functions. Growth 86 rate study for Calu-3 cells. Inductively coupled plasma mass 87 spectrometry (ICP-MS). (PDF)

\section{AUTHOR INFORMATION}

\section{Corresponding Author}

90 *Email: Frankie.Rawson@nottingham.ac.uk

\section{Author Contributions}

92

93

94

\section{ACKNOWLEDGMENT}

98 The authors thank the Engineering and Physical Sciences Research Council (EPSRC; EP/L01646X), The University of Nottingham CDT in Advanced Therapeutics and Nanomedicines, and Boots UK Ltd for financial Support. We would also like to thank the Division of Agriculture \& Environmental Sciences School of Biosciences (Sutton Bonington Campus $\mathrm{Nr}$ Loughborough, LE12 5RD) for their help with ICP-MS samples analysis.

\section{REFERENCES}

(1) Rawson, F. J.; Garrett, D. J.; Leech, D.; Downard, A. J.; Baronian, K. H. R. Biosens. Bioelectron. 2011, 26 (5), $2383-$ 2389

(2) Haslett, N. D.; Rawson, F. J.; Barriëre, F.; Kunze, G.; Pasco, 
N.; Gooneratne, R.; Baronian, K. H. R. Biosens. Bioelectron. 2011, 26 (9), 3742-3747.

(3) Herst, P. M.; Tan, A. S.; Scarlett, D.-J. G.; Berridge, M. V. Biochim. Biophys. Acta 2004, 1656 (2-3), 79-87.

(4) Lane, D.; Bae, D.-H.; Merlot, A.; Sahni, S.; Richardson, D. Nutrients 2015, 7 (4), 2274-2296.

(5) Ghio, A. J.; Turi, J. L.; Yang, F.; Garrick, L. M.; Garrick, M. D. Biol. Res. 2006, 39 (1), 67-77.

(6) Ghio, A. J. Biochim. Biophys. Acta - Gen. Subj. 2009, 1790 (7), 731-739.

(7) Lane, D. J. R.; Lawen, A. Anal. Biochem. 2008, 373 (2), 287 295.

(8) Kostas Pantopoulos, Suheel Kumar Porwal, Alan Tartakoff, and L. D. Mechanisms of mammalian iron homeostasis; 2012; Vol. 29.

(9) Lieu, P. T.; Heiskala, M.; Peterson, P. a.; Yang, Y. Mol. Aspects Med. 2001, 22 (1-2), 1-87.

(10) Kamga, C.; Krishnamurthy, S.; Shiva, S. Nitric Oxide - Biol. Chem. 2012, 26 (4), 251-258.

(11) Hentze, M. W.; Muckenthaler, M. U.; Andrews, N. C. Trends Biochem. Sci. 2005, 30 (3), 285-297.

(12) Lane, D. J. R.; Lawen, A. Free Radic. Biol. Med. 2009, 47 (5), 485-495.

(13) Medina, M. Á.; Castillo-Olivares, A. Del; De Castro, I. N. BioEssays 1997, 19 (11), 977-984.

(14) Wolvetang, E. J.; Larm, J. A.; Moutsoulas, P.; Lawen, A. Cell Growth Differ. 1996, 7 (10), 1315-1325.

(15) Lawen, A.; Baker, M. A.; Malik, S. Protoplasma 1998, 205 (1), 10-20.

(16) May, J. M. FASEB J. 1999, 13 (9), 995-1006.

(17) McKie, A. T.; Barrow, D.; Latunde-Dada, G. O.; Rolfs, A.; Sager, G.; Mudaly, E.; Mudaly, M.; Richardson, C.; Barlow, D.; Bomford, A.; Peters, T. J.; Raja, K. B.; Shirali, S.; Hediger, M. A.; Farzaneh, F.; Simpson, R. J. Science 2001, 291 (5509), 1755-1759.

(18) Lane, D. J. R.; Lawen, A. BioFactors 2009, 34 (3), 191-200.

(19) Lane, D. J. R.; Lawen, A. Free Radic. Biol. Med. 2009, 47 (5), 485-495.

(20) Su, D.; May, J. M.; Koury, M. J.; Asard, H. J. Biol. Chem. 2006, 281 (52), 39852-39859.

(21) Turi, J. L.; Wang, X.; McKie, A. T.; Nozik-Grayck, E.; Mamo, L. B.; Crissman, K.; Piantadosi, C. A.; Ghio, A. J. Am J Physiol Lung Cell Mol Physiol 2006, 291 (2), L272-80.

(22) Kovar, J.; Neubauerova, J.; Cimburova, M.; Truksa, J. Blood Cells. Mol. Dis. 2006, 37, 95-99.

(23) Loke, S.; Siddiqi, N. J.; Alhomida, A. S.; Kim, H.; Ong, W. Neuroscience 2013, 245, 179-190.

(24) Balusikova, K.; Neubauerova, J.; Dostalikova-Cimburova, M.; Horak, J.; Kovar, J. Mol. Cell. Biochem. 2009, 321 (1), 123-133.

(25) Anderson, G. J. Journal of Gastroenterology and Hepatology (Australia). 1999, pp 105-108.

(26) Brissot, P.; Ropert, M.; Le Lan, C.; Loréal, O. Biochim. Biophys. Acta - Gen. Subj. 2012, 1820 (3), 403-410. Warburg, O. ed. J. Am. Med. Assoc. 1931, 96, 1982-2309. Herst, P. M.; Berridge, M. V. Biochim. Biophys. Acta -
Bioenerg. 2007, 1767 (2), 170-177.

Oakhill, J. S.; Marritt, S. J.; Gareta, E. G.; Cammack, R.; McKie, A. T. Biochim. Biophys. Acta - Bioenerg. 2008, 1777 (3), 260-268.

(30) Mackenzie, B.; Ujwal, M. L.; Chang, M.-H. H.; Romero, M. F.; Hediger, M. a. Pflugers Arch. Eur. J. Physiol. 2006, 451 (4), 544-558

(31) Mackenzie, B.; Takanaga, H.; Hubert, N.; Rolfs, A.; Hediger, M. a. Biochem. J. 2007, 403 (1), 59-69.

(32) Rawson, F. J.; Downard, A. J.; Baronian, K. H. Sci. Rep. 2014, 4, 5216.

(33) Baronian, K.; Downard, A.; Lowen, R.; Pasco, N. Appl. Microbiol. Biotechnol. 2003, 60 (1-2), 108-113.

(34) McDowall, J. S.; Ntai, I.; Honeychurch, K. C.; Hart, J. P.; Colin, P.; Schneider, B. L.; Brown, D. R. Mol. Cell. Neurosci. 2017, 85 (Supplement C), 1-11.

(35) Herst, P. M.; Berridge, M. V. Biochim. Biophys. Acta Bioenerg. 2007, 1767 (2), 170-177.

(36) Berridge, M. V.; Herst, P. M.; Tan, A. S. Mitochondrion 2010, 10 (6), 584-588.

(37) Scarlett, D. J.; Herst, P.; Tan, a; Prata, C.; Berridge, M. Biofactors 2004, 20 (4), 199-206.

(38) Avron, M.; Shavit, N. Anal. Biochem. 1963, 6 (6), 549-554.

(39) Lawen, A.; Lane, D. J. R. Antioxid. Redox Signal. 2013, 18 (18).

(40) Ganz, T. Physiol. Rev. 2013, 93 (4), 1721-1741.

(41) Kissinger, P. T.; Heineman, W. R. J. Chem. Educ. 1983, 60 (9), 702.

(42) Sun, I. L.; Crane, F. L.; Grebing, C.; Löw, H. J. Bioenerg. Biomembr. 1984, 16 (5), 583-595.

(43) Armbruster, D. A.; Pry, T. Clin. Biochem. Rev. 2008, 29 Suppl 1 (August), S49-52.

(44) Blanco, R.; Iwakawa, R.; Tang, M.; Kohno, T.; Angulo, B.; Pio, R.; Montuenga, L. M.; Minna, J. D.; Yokota, J.; Sanchez, M. Hum. Mutat. 2010, 30 (8), 1199-1206.

(45) Lieber, M.; Todaro, G.; Smith, B.; Szakal, A.; Nelson-Rees, W. Int. J. Cancer 1976, 17 (1), 62-70.

(46) Shen, B. Q.; Finkbeiner, W. E.; Wine, J. J.; Mrsny, R. J.; Widdicombe, J. H. Am. J. Physiol. 1994, 266 (5 Pt 1), L493501.

(47) Chan, K.-S.; Koh, C.-G.; Li, H.-Y. Cell Death Dis. 2012, 3, e411.

(48) Cairns, R. A.; Harris, I. S.; Mak, T. W. Nat. Rev. Cancer 2011, 11 (2), 85-95.

(49) Keilin, F. R. S.; Hartree, E. . Nature 1946, 157, 210.

(50) Mathiasen, A. B.; Hansen, L.; Friis, T.; Thomsen, C.; Bhakoo, K.; Kastrup, J. Stem Cells Int. 2013, 2013.

(51) Mojić, M.; Bogdanović Pristov, J.; Maksimović-Ivanić, D.; Jones, D. R.; Stanić, M.; Mijatović, S.; Spasojević, I. Sci. Rep. 2014, 4, 5955

(52) Kumar, M.; Singh, G.; Arora, V.; Mewar, S.; Sharma, U.; Jagannathan, N. R.; Sapra, S.; Dinda, A. K.; Kharbanda, S.; Singh, H. Int. J. Nanomedicine 2012, 7 (September), 35033516.

(53) Ly, J. D.; Lawen, A. Redox Rep. 2003, 8 (1), 3-21. 
